\title{
AN ALGEBRAIC MODEL OF HIGH-ALTITUDE AIRCRAFT DECOMPRESSION AND EMERGENCY DESCENT
}

\author{
Nihad E. DAIDZIC \\ AAR Aerospace Consulting, LLC, P.O. Box 208, Saint Peter, Minnesota 56082-0208, United States \\ E-mail: Nihad.daidzic@aaraerospacecon.com,aaraerospace@cs.com
}

Received 20 July 2017; accepted 12 September 2017

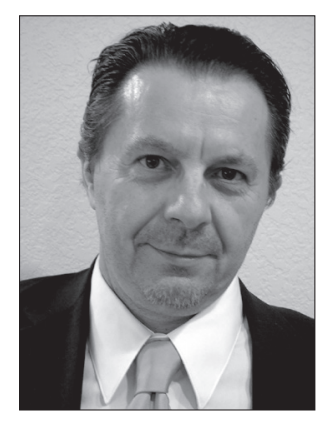

\begin{abstract}
Nihad E. DAIDZIC is the president of AAR Aerospace Consulting, L.L.C. He is also a full professor of Aviation, adjunct professor of Mechanical Engineering, and research graduate faculty at Minnesota State University. His PhD is in fluid mechanics and $S c D$ in mechanical engineering. He was formerly a staff scientist at the National Center for Microgravity Research and the National Center for Space Exploration and Research at NASA Glenn Research Center in Cleveland, $\mathrm{OH}$. He also held various faculty appointments at Vanderbilt University, University of Kansas, and Kent State University. His current research interest is in theoretical, experimental, and computational fluid dynamics, micro- and nano-fluidics, aircraft stability, control, and performance, mechanics of flight, piloting techniques, and aerospace propulsion. Dr. Daidzic is an FAA certified Airline Transport Pilot and an FAA certified "Gold Seal" flight instructor with flight experience in airplanes, helicopters, and gliders.
\end{abstract}

\begin{abstract}
An emergency descent maneuver initiated by pilots shortly after the onset of the decompression recognition was developed for subsonic, supersonic and hypersonic cruisers. Among other findings, the times when a passenger cabin is exposed to altitudes above 25,000 and 40,000 ft and the maximum cabin altitude reached are estimated. An airplane descent aerodynamic model was incorporated for high-speed and low-speed high-drag emergency descents. Airplane cabin atmosphere is assumed to be isothermal. The environmental atmosphere is simulated using the NLPAM nonlinear atmospheric model valid up to 47 geopotential kilometers. Rapid and slow decompressions at several discrete cruising altitudes ranging from 12 to $40 \mathrm{~km}$ and varying pilot reaction times in initiating the emergency descent were simulated. The main motivation for this work was to estimate times and altitudes a cabin reaches during depressurization for various flight conditions. This model can be utilized in optimizing the emergency-descent piloting techniques, calculating oxygen supplies, evaluating aeromedical factors, estimating harmful exposures to low pressures, and for other important high-altitude aircraft operations.
\end{abstract}

Keywords: aircraft decompression, emergency descent, atmospheric models, limiting aircraft airspeeds, unsteady descent, aviation regulatory limits, time of useful consciousness, supplemental oxygen.

\section{Introduction}

The risk of high-altitude airplanes, orbital and suborbital spaceplanes, and spacecraft decompressions poses a great risk to the crew and passengers as well as for an aircraft's structural integrity. Future Supersonic Transport (SST) and extreme-altitude hypersonic transport (HST) will be exposed to extreme (space-like) environmental conditions. The Anglo-French Concorde and the Soviet/Russian Tupolev TU-144 commercial transport SSTs operated successfully at altitudes between 50,000 and 60,000 ft. There will always be a risk of cabin decompression caused by human life-support system equipment failures and structural failures (Macarthur 1994), micro-meteorite impacts (Whipple 1963), uncontained engine damage (e.g., blade separation), etc. In fact, the early jet-age (1950's) was plagued by catastrophic structural failures and explosive/rapid decompressions at high altitudes (Macarthur 1994). In the case of explosive and rapid decompressions, the aircraft's cabin will equalize with the ambient pressure before the flight crew can initiate an emergency descent (ED). However, in the case of slower decompressions, the ED dynamics plays an important part in the local cabin-atmosphere evolution. Hence, to account for all important temporal effects during aircraft decompressions, the aircraft's ED flight mechanics must also be considered.

The purpose of this research paper is to present a simple and useful algebraic model of aircraft decompression 
and ED dynamics. ED is unlike any other airplane descent maneuver, as it occurs on the edge of the high-speed buffet limit and Mach compressibility effects with significant transonic wave drag components. We assumed the local aircraft cabin atmosphere to remain isothermal despite air cooling during depressurization expansion. No re-pressurization was considered. Isothermal ISOAM and the nonlinear parabolic NLPAM environmental atmosphere models, developed by Daidzic (2015b), are used in decompression and ED dynamics. The aircraft considered here are high-subsonic transport-category (T-category) airplanes cruising in the 30,000-45,000 feet range (9-14 km), SST flying at about $60,000 \mathrm{ft}(18 \mathrm{~km})$, and future HST spaceplanes flying at altitudes of about 130,000 feet $(40 \mathrm{~km})$. The effect of flight crew response time, aircraft descent configuration, and vessel breach size on ED dynamics is examined. The advanced analysis based on a complex differential model of airplane decompressions and descent flight mechanics will be presented in a subsequent publication.

A pressure vessel (hull) of a typical high-altitude aircraft is of a semi-monocoque design and may have one or two aisles, floor vent panels, and a cargo compartment beneath the passenger cabin. The fuselage cross section is typically ovoid or circular. The hull consists of several individual pressurized compartments normally communicating with each other through air venting systems. The pressure hull is closed by aft and forward pressure bulkheads, which are safety critical components. The cargo compartments and electronics/ equipment cooling bays receive "used" air from the passenger and crew compartments. A significant amount of air inevitably escapes through uncontrolled leaks. Outflow valves control the cabin altitude (CA), while the inflow of conditioned air occurs at an almost constant rate. A schematic of a simplified vertical flight profile and pressurization schedule is illustrated in Figure 1. During taxiing, the CA is typically set by cabin pressure controllers (CPC) to $200 \mathrm{ft}$ below the field elevation (+0.1 PSID) to prevent pressure bumps, pressurize door seals, and to structurally strengthen the fuselage for ground loads.

A pressurized vessel will always leak, and the leaks will increase the larger the pressure differential is. Modern airplane designs result in cabin climbs of about 1,000-2,000 fpm due to uncontrolled leaking at high altitudes. Thus, a constant inflow of conditioned air is necessary. The leakage characteristics will depend on the airplane's age and altitudes flown. It is impossible, or rather impractical, to completely seal the pressure vessel of an airplane, nor is it necessary. However, minimizing uncontrolled leaks lowers the engine specific fuel consumption. Structural and functional tests are required for pressurized aircraft certification (e.g., 14 CFR 25.843). The design and function of airplane doors and hatches are regulated by CFR 25.783 (FAA 2015a) and guidance in demonstrating compliance and supplemental material is given in Advisory Circular (AC) 25.783-1A (FAA 2005). The air-conditioning and pressurization system for airplanes certified for and operating above 25, $000 \mathrm{ft}$ must be designed so as to allow the remaining air-pack to maintain CA at or below 15,000 ft at all times, as specifically stated in CFR 25.841 (FAA 2015a). Accordingly, every airplane certified to fly above $25,000 \mathrm{ft}$ must have means to limit the CA to $15,000 \mathrm{ft}$ in the event of any reasonably probable malfunction or failure of the pressurization system (Jeppesen 2007).

Outflow valves control the cabin atmosphere. The CPC adjusts outflow valves to maintain a programmed pressurization mode. Once the maximum operational cabin pressure differential (PSID) is reached, no further increase is possible. The safety outflow valves will leak excess cabin air to maintain structural integrity of the pressure hull if the airplane continues to climb.

Many aviation legal requirements are directing the design and operation of pressurization, ventilation and oxygen supply in T-category airplanes certified under FAA/EASA rules CFR/CS 25, such as, 25.365(d) (pressurized compartment loads), 25.831 (ventilation), 25.841 (pressurized cabins) and 25.1447. The FAA has issued AC 25-20 (FAA 1996) to set forward guidance on methods of compliance with pressurization requirements of part 25 certified airplanes. The supplemental oxygen requirements for part 121 (FAA 2014) operational regulation are given in 121.329 (supplemental $\mathrm{O}_{2}$ for sustenance), 121.333 (emergency descent), 121.325 (equipment standard), 121.337 (protective breathing equipment). According to current CFR 25.841(2), the CA should not exceed 25,000 ft for more than 2 minutes and 40,000 $\mathrm{ft}$ must not be exceeded for any duration (FAA 2015a). However, A380 has received exemption allowing the maximum CA of 43,000 $\mathrm{ft}$ with the maximum CA duration above $40,000 \mathrm{ft}$ of one minute. The crew supplemental oxygen regulations require a quick-donning mask (CFR 25.1447) be available to both pilots for flight above 25,000 ft and below 41,000 ft in which case it

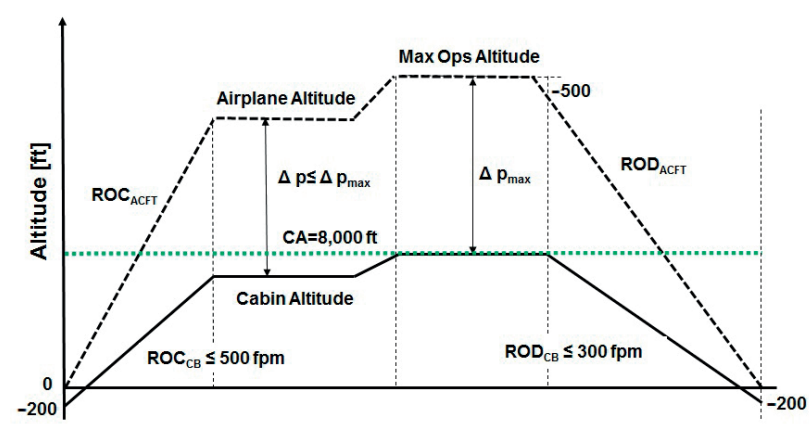

Fig. 1. Simplified aircraft and CA pressurization dynamics. Not to scale 
does not have to be on unless one pilot leaves the cockpit (e.g., for physiological reasons). Above 41,000 ft, at least one pilot must have donned and be using an oxygen mask at all times as per CFR 121.333 (FAA 2014). This is for the reason that the Time of Useful Consciousness (TUC) is practically only $10-15$ seconds above $41,000 \mathrm{ft}$. A quick-donning mask has to be put on within 5 seconds and each pilot must personally preflight his oxygen equipment before the flight (FAA 2015a).

Once the outflow valves are fully closed, any additional loss of cabin air will lead to internal air pressure, density, temperature, and humidity reduction. The rate at which this occurs will indicate if the decompressions are explosive (less than 0.5 second), rapid ( 0.5 to 10 seconds), fast (10-100 seconds), slow (100--1,000 seconds), or very slow (> 1,000 seconds). Normally, the pressurized compartments communicate through passive vents. As a safety measure, active vents (dado or equalization panels) are incorporated to quickly relieve the pressure difference and reduce the structural loads on an airframe's internal structure. The vent box in a typical FAR/CS 25 airplane incorporates a dadopanel and a louvered air grille. This is a part of a hinged and spring-loaded door which provides high-capacity air-flow capability in the case of significant pressure difference. There have been several airplane accidents where the cargo compartment rapidly depressurized due to cargo door failure with the cabin floor subsequently collapsing due to an excessive pressure difference. A modern T-category airplane will have two outflow valves, each powered by two or three AC and DC e-motors. Also, at least two positive pressure relief valves (PPRV) are installed to vent excess air if the pressure differential exceeds the operational maximum pressure differential PSID by about 0.5 psi. At least two inward relief or negative pressure relief valves (NPRV) are also installed with a similar $0.5 \mathrm{psi}(3.45 \mathrm{kPa})$ pressure difference threshold to open. They are flapper-type spring-loaded valves that open inside, like a letterbox. Their role is to prevent cabin pressure being significantly lower than the environmental pressure.

The design and operation of human life-support and Environmental Control Systems (ECS) that include air-conditioning, ventilation, distribution, supplemental oxygen, and pressurization control systems for high-altitude flying airplanes is a complex subject. An interested reader may consult references, such as, Gooch (1993), Jeppesen (2007), Moir and Seabdridge (2008, 2013), Moir et al. (2013), and Wild (1996) for more details. A particular ECS system installed in the B767-300ER is discussed in Hunt and Space (1994) and Hunt et al. (1995). Gooch (1993) specifically discusses the B757200 and B767-200 systems with many operational details. A good summary of high-altitude high-speed operations and hazards for pilots and operators is given in AC 61-107B (FAA 2015b). Macarthur (1994) and Bibel (2008) provide a basic forensic study and description of some serious incidents and fatal airplane decompression accidents.

Specifically, Filippone (2007) discusses a steep-descent maneuver of a T-category aircraft, but his work is more in connection with steep instrument and visual approaches which are a low-speed high-drag maneuver not involving high-speed aerodynamics. Lowry (2002) presents a 3D aerodynamic model for not necessarily small inclination angles and low AOA's. This model was designed mostly for low-speed GA aircraft and does not incorporate wave drag. An exhaustive review of references addressing aircraft decompressions is given in Daidzic and Simones (2010). Also various analytical and numerical polytropic expansion models were used to simulate decompressions in small and large airplanes. Daidzic $(2010,2011)$ tackled propulsion, aerodynamic, and human physiological challenges of very high altitudes, including suborbital and orbital spaceplane flights. We also mention a recent contribution by Pagani and Carrera (2016) treating active venting. None of the aforementioned sources have dealt with the ED dynamics explicitly.

\section{Mathematical model and methods}

The essentials of compressible flow between two pressurized compartments (including atmosphere as an infinite compartment) are given in Daidzic and Simones (2010). The air outflow is continuously changing as both internal and external pressures are varying. However, for an algebraic-model analysis, the average rates are calculated. The local cabin atmosphere and the environmental atmosphere were modeled using the ISOAM and the nonlinear parabolic NLPAM atmospheric models. An ED maneuver requires flight-mechanics computations of unpowered fast and steep descents. Few working equations are given to estimate the angles-of-descent (AOD) and rates-of-descent (ROD).

\subsection{Atmospheric models}

Three atmospheres in the range of surface to $47 \mathrm{~km}$ were employed. We use the International Standard Atmosphere (ISA) for aircraft performance computations. Unlike several ISA's discrete-regions, the environmental NLPAM introduces smooth and continuous changes of atmospheric parameters following the ISA closely (Daidzic 2015b). ISOAM is used for the local cabin atmosphere. Air is assumed to be an ideal-gas dry air-mixture with many properties summarized in Daidzic (2015a). 


\subsubsection{Cabin atmosphere}

The airplane cabin's "atmosphere" is essentially isothermal during normal operations. An aircraft's ECS maintain a constant cabin air temperature while the airplane is climbing, descending, or cruising. The CA should not exceed 8,000 $\mathrm{ft}$ under the current regulations. So, we can write for the cabin ISOAM (Daidzic 2015b):

$$
\begin{aligned}
& \delta_{C B}=\frac{p_{C B}}{p_{C B}^{S L}}=\exp \left(-\kappa_{C B} \cdot H_{C B}\right) \\
& \theta_{C B}\left(H_{C B}\right)=\frac{T_{C B}}{T_{C B}^{S L}}=\text { const. } \quad \sigma=\frac{\rho}{\rho_{S L}},
\end{aligned}
$$

where $\kappa_{C B}=g_{o} /\left(R \cdot T_{C B}\right)=1 / H_{C B}^{*}=$ const. The CA is expressed in terms of cabin pressure accordingly:

$$
H_{C B}=-\left(R \cdot T_{C B} / g_{o}\right) \cdot \ln \delta_{C B}=-H_{C B}^{*} \cdot \ln \delta_{C B} \quad \delta_{C B} \leq 1 .
$$

The ISOAM cabin-atmosphere scale-height $H_{C B}^{*}$ is about 8,635 meters at a cabin air temperature of $295 \mathrm{~K}$ $\left(22^{\circ} \mathrm{C}\right)$. The ISOAM terrestrial atmosphere model uses a constant air temperature of $275 \mathrm{~K}$ with an associated scale-height of about 8,050 m (Daidzic 2015b). During steady climbs and descents, the aircraft pressurization systems are in dynamic balance. The CA is increasing, i.e., air pressure and density are decreasing at an approximately constant temperature (isothermal expansion). During climb, the CA is increasing and the rate-of-climb (ROC) is typically at, or less than, $500 \mathrm{fpm}$. The controlled discharge through the outflow valve(s) plus uncontrolled leaks exceed the total inflow of conditioned air resulting in:

$$
\begin{aligned}
& \frac{d p_{C B}}{d t}<0 \quad \frac{d H_{C B}}{d t}>0 \\
& \dot{m}_{\text {in }, C B}<\dot{m}_{\text {out }, \text { leak }}+\dot{m}_{\text {out }, \text { valve }} \quad V_{C B}=\text { const }
\end{aligned}
$$

During descent, the CA ROD is typically less than $300 \mathrm{fpm}$ for human comfort resulting in:

$$
\begin{aligned}
& \frac{d p_{C B}}{d t}>0 \quad \frac{d H_{C B}}{d t}<0 \\
& \dot{m}_{\text {in, } C B}>\dot{m}_{\text {out }, \text { leak }}+\dot{m}_{\text {out }, \text { valve }} \quad V_{C B}=\text { const }
\end{aligned}
$$

The cabin ROC can be estimated from the cabin pressure change during decompression:

$\frac{d p_{C B}}{d t}=\frac{d p_{C B}}{d H_{C B}} \cdot \frac{d H_{C B}}{d t} \Rightarrow \frac{d H_{C B}}{d t}=R O C_{C B}=\frac{d p_{C B} / d t}{d p_{C B} / d H_{C B}}$. (3)

While during rapid decompressions, the cabin air will cool down somewhat, the effect of continuous inflow of warm air-conditioned air, water-vapor condensation, and the limited re-pressurization from communicating neighboring pressurized compartment results in the ISOAM still being a reasonable approximation.

\subsubsection{Terrestrial atmosphere}

The ISA consists of many discrete layers with discontinuous temperature lapse rates (TLRs), which complicates the computations (Daidzic 2015a). Instead, the NLPAM model of the ISA troposphere-stratosphere, recently developed by Daidzic (2015b), is used. In the NLPAM model, the temperature versus geopotential height $H$ (in meters) is expressed with a smooth polynomial:

$$
T_{\text {NLPAM }}(H)=a_{0}+a_{1} \cdot H+a_{2} \cdot H^{2} \quad[\mathrm{~K}] \quad H \leq 47,000 \mathrm{~m},
$$

where $a_{0}=288.15, a_{1}=-5.7589736 \times 10^{-3}, a_{2}=$ $+1.1460922 \times 10^{-7}, \mathrm{D}=a_{1}^{2}-4 a_{0} a_{2}=-9.89452 \times 10^{-5}$ (Daidzic 2015b). Unlike in the ISA, the TLR is continuous. The NLPAM non-dimensional temperature and pressure become:

$$
\begin{aligned}
& \theta_{\text {NLPAM }}(H)=T_{a}(H) / T_{a, S L}= \\
& 1-1.9986027 \times 10^{-5} H+3.977415235 \times 10^{-10} H^{2} ; \\
& \sigma_{a}(H)=\delta_{a}(H) / \theta_{a}(H) \\
& \delta_{N L P A M}(H)=p_{a} / p_{a, S L}=2.7191 \times 10^{-2} \cdot \delta_{0} \cdot \\
& \exp \left[-6.86896 \cdot \tan ^{-1}\left(-0.5789589+2.30437 \times 10^{-5} \cdot H\right)\right] .
\end{aligned}
$$

If the average height (about $237 \mathrm{~m}$ ) of the terrestrial topography (Trenberth, Smith 2005) is neglected, then $\delta_{o}=1$. The relationship between the geopotential $H$ and the orthometric $z$ altitudes, due to the spherical Earth Newtonian law of gravitation, is given in Daidzic (2015a, 2015b). The difference between the geopotential and the orthometric (MSL) altitude for the troposphere and stratosphere are neglected (Daidzic 2015a, 2015b). The linear temperature profile in the ISA troposphere $(0-11 \mathrm{~km})$ is expressed as $\theta_{I S A}(H)=1-2.2557696 \times 10^{-5} H$, which is a bit steeper than in the NLPAM troposphere. The NLPAM has no practical tropopause and the zero TLR is reached at about $25 \mathrm{~km}$, after which the TLR becomes positive.

\subsection{Aircraft emergency descent maneuver}

If an airplane is depressurized, an ED will be initiated. The ED maneuver will bring an aircraft into a naturally breathable atmosphere. The ED can be flown manually or by using autoflight systems. If autopilots (AP) and auto-throttles (AT) are used, the ED maneuver typically consists of these steps.

1. Donning the oxygen mask, $100 \% \mathrm{O}_{2}$, and establishing crew communication (memory items).

2. Establishing ED (action items):

a) altitude, set level-off altitude on the MCP ALT window (5,000-10,000 ft MSL terrain permitting);

b) pitch channel, FLCH Mach/IAS speed/Machhold mode;

c) roll channel, turn the HDG knob and push HDG select on the MCP to turn away from the existing flight course and facilitate a faster banked turn entry;

d) spoilers/speedbrakes, flight detent;

e) speed, set $M_{M O} / V_{M O}$ in the MCP speed (or other limiting airspeed);

f) throttles, retard smoothly, verify idle detent, and ignition ON (AUTO or override); 
g) transponder set at 7700 ;

h) ATC, inform/notify/advise;

i) cabin signs, ON;

j) passenger $\mathrm{O}_{2}, \mathrm{ON}$ (required if CA above $14,000 \mathrm{ft}$ ).

The exact procedure may vary slightly for different airplane make and models as well as operators. Few piloting and flight-training oriented references give some generic or airplane specific ED procedures (Davies 1971; Ray 1999, 2000; Webb, Walker 2004). Davies (1971) discussed different ED maneuvers, including high-speed and slow-speed high-drag descent with or without landing gear extended for a B747-100. According to flight and certification tests of B747-100 prototypes, a highspeed descent at $\mathrm{M}_{\mathrm{MO}} / \mathrm{V}_{\mathrm{MO}}$ from FL300 to FL150 would take about 2 minutes and 7 seconds. If first slowing down to $\mathrm{V}_{\mathrm{LO}}$ of 270 KIAS, extending landing gears, and then descending at $\mathrm{V}_{\mathrm{LE}}$ of 320 KIAS, the same altitude loss would occur in 2 minutes and 25 seconds (Davies 1971). Thus, the first high-speed scenario would result in an average ROD of 7,087 fpm, while the landing gear extended high-drag ED would result in an average ROD of about $6,207 \mathrm{fpm}$. The $2^{\text {nd }}$ scenario, although slower, would be more appropriate in specific cases. For example, a slowspeed high-drag ED is used when the structural integrity of the aircraft is in doubt or when descending through severe/extreme turbulence. Having landing gear down and descending at $\mathrm{V}_{\mathrm{LE}}$ limit is also required with the wheel-well fire. Ray $(1999,2000)$ highlights ED procedures for the B737 and B757/767 types. A 10,000 ft visual and audio CA cockpit warning alerts the flight crew to a depressurization event. It is assumed that the airplane will descend to at least 10,000 ft or preferably lower (local terrain permitting), but not less than the applicable Minimum En-route Altitude (MEA).

Oxygen requirements for each occupant (FAA 2014) are based on the amount of time it takes an aircraft to descend from cruise altitudes to less than 10,000 $\mathrm{ft}(3 \mathrm{~km})$. For example, FAR 91.211(b) requires a minimum of 10 minutes for passengers $\mathrm{O}_{2}$ supply. Ideally, the flight crew will initiate the ED within 10-15 seconds. However, FAA's AC 25-20 (FAA 1996) references piloted studies done in early 1950's and 1960's and simulator tests, where it took pilots 17 seconds on average just to don the oxygen masks. This reaction time was based on $75 \%$ of pilots completing the task of donning oxygen masks. The study mentioned in AC 25-20 also disclosed that it took up to additional 5 seconds to actually start the ED (FAA 1996). Essentially, that implies that 22 seconds elapsed after the decompression onset before the actual initiation of the ED.

A decompression incident that occurred in August 2005 to a B737-300 flying from Spain to UK at FL360 resulted in an $\mathrm{ED}$ that took about 6.5 minutes to descend to $10,500 \mathrm{ft}$. According to the Quick Access Recorder and Cockpit Voice Recorder, the flight crew properly diagnosed decompression and executed the ED. The average ROD was $4,300 \mathrm{fpm}$ with the maximum instantaneous ROD of 6,200 fpm. The maximum descent angle reached $4.92^{\circ}$. Depending on the rupture geometry and pressure differences, the CA increases at an average rate, typically, between 1,000 (very slow) and 300,000 fpm (rapid).

\subsection{Algebraic emergency descent model}

A simple linear algebraic model was developed to simulate the decompression and ED dynamics. While this may seem to be an oversimplification of the strongly nonlinear compressible flow phenomena, the fact is that, initially, the cabin air outflow due to breach will be chocked (Daidzic, Simones 2010), and the outflow is directly proportional to the cabin pressure, assuming that the expansion is closely isothermal. Hence, the outside atmosphere does not affect the outflow in any way until the critical pressure ratio is reached, which happens later during the decompression event. A simplified aircraft decompression and ED dynamics is illustrated in Figure 2. The maximum cabin altitude $\mathrm{CA}_{\max }$ that is reached depends on the initial $\mathrm{CA}_{0}$ and $\mathrm{FL}_{0}$. All events are measured from the start of the decompression event $T_{0}$. The average human TUC physiological curve is complicated and depends on many factors not considered here. It is shown as a reference only and should not be scaled. The time elapsed for the flight crew to don oxygen masks and use them is designated as $T_{O X}$ and should occur before the TUC for safety reasons. The time it takes the cabin to rise to FL100 and trigger the cockpit warning is designated as $T_{100}$. Using average $\mathrm{ROC}_{\mathrm{CB}}$ for the CA change, average rate $\mathrm{ROD}_{\text {Acft }}$ for airplane altitude, and accounting for the $\mathrm{ED}$ reaction time, the $\mathrm{T}_{\mathrm{ED}}$ results in:

$C A_{\max }=C A_{0}+\frac{F L_{0}-C A_{0}}{1+\xi}+\frac{R O D_{A c f t} \cdot T_{E D}}{1+\xi} \quad \xi=\frac{R O D_{A c f t}}{R O C_{C B}} \leq \geq 1$.

An important time in the decompression event is the instant the cabin reaches $10,000 \mathrm{ft}$ and the existing CA when the ED starts. Hence, we can write for the CA at $\mathrm{T}_{\mathrm{ED}}: C A_{E D}=C A_{0}+T_{E D} \cdot R O C_{C B}$. For a CA to reach 25,000 $\mathrm{ft}$, the following condition exists:

$\xi_{250} \leq \frac{\left(F L_{0}-25,000\right)+R O D_{A c f t} \cdot T_{E D}}{\left(25,000-C A_{0}\right)} \quad C A_{\max } \geq 25,000$.

Similarly, the conditions for the CA to reach FL400 or $\xi_{400}$ are estimated. All rates of climbs and descents are regarded as positive values in Eq. (7). The time to reach the peak altitude and 25,000 ft (if applicable), respectively, is given as:

$$
T_{P K}=\frac{C A_{\max }-C A_{0}}{R O C_{C B}} \quad T_{250 b}=\frac{25,000-C A_{0}}{R O C_{C B}} .
$$




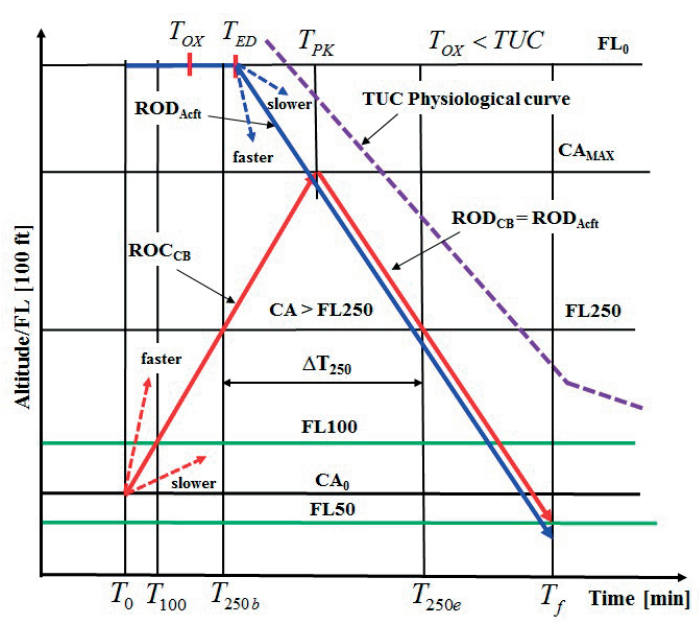

Fig. 2. Simple algebraic CA dynamics versus the ED flight profile. Not to scale

After reaching the maximum CA, the cabin will be descending at the same rate and slightly lagging behind the environmental pressure. The time for the cabin to descend back to $25,000 \mathrm{ft}$ is:

$t=T_{P K}+\frac{C A_{\max }-C A}{R O D_{A c f t}} \quad T_{250 e}=T_{P K}+\frac{C A_{\max }-25,000}{R O D_{A c f t}}$
$\Delta T_{250}=T_{250 e}-T_{250 b}>0$.

Similar computations can be made for a FL400 cabin altitude. The time the airplane and the cabin atmosphere reach (final) 5,000 ft after the decompression onset is:

$$
T_{50}=T_{E D}+\frac{F L_{0}-5,000}{R O D_{\text {Acft }}} .
$$

\subsection{Airplane emergency descent aerodynamic model}

A steady-state descent gradient for the required ED configuration and (flight) idling jet engines is:

$$
\begin{aligned}
& \sin \gamma=\left(\frac{T}{W}\right)_{\text {idle }}-\frac{\cos \gamma}{(L / D)} \approx\left(\frac{T}{W}\right)_{\text {idle }}-\frac{1}{E}=-E_{\text {eff }}^{-1} \Rightarrow \\
& \gamma=-\sin ^{-1}\left(E_{\text {eff }}^{-1}\right) .
\end{aligned}
$$

The steady-state ED descent angles are typically less than 10 degrees, hence $\cos \gamma \approx 1$ and $\tan \gamma \approx \sin \gamma \approx \gamma$. Flight idle thrust is about $8-12 \%$ of the maximum at a given altitude (depends on the power off-takes for aircraft systems) and is a small positive contribution to unpowered glide aerodynamic efficiency $E_{\text {aero }}\left(E_{\text {eff }}>\right.$ $\left.E_{\text {aero }}\right)$. The Mach-number dependent $E$ is (Daidzic 2016):

$$
\begin{aligned}
& E(M)=\frac{C_{L}}{C_{D}(M)}=\frac{C_{L}}{C_{D, 0}(M)+K(M) \cdot C_{L}^{2}} \\
& C_{L} \approx \frac{W}{q_{\max } S_{r e f}} .
\end{aligned}
$$

In most cases, the ED maneuver is conducted in a clean configuration with speed-brakes (flight spoilers) fully extended and is then flown at $\mathrm{V}_{\mathrm{MO}} / \mathrm{M}_{\mathrm{MO}}$ limit (it is permissible to exceed those airspeeds by a few knots). $\mathrm{M}_{\mathrm{MO}}$ is close to the airplane's drag-divergence Mach $\left(\mathrm{M}_{\mathrm{DD}}\right)$ and provides a margin from shock-stall and highspeed instabilities and control problems (Daidzic 2016). On the other hand, the $\mathrm{V}_{\mathrm{MO}}$ signifies the max-Q compressible flow stagnation-pressure limit and the onset of aerodynamic flutter structural and control problems. More information on the $\mathrm{V}_{\mathrm{MO}}$ and $\mathrm{M}_{\mathrm{MO}}$, and how it is related to other flight testing airspeeds can be found in FAA $(2012,2015 a)$. At 340 KEAS dynamic pressure is about 2.72 psi (or $18.76 \mathrm{kPa}$ ). At high-subsonic Mach numbers transonic wave-drag contributes noticeably to the total drag and $E$ will be decreasing with an increasing Mach number. For a typical T-category subsonic airplanes at $\mathrm{V}_{\mathrm{MO}} / \mathrm{M}_{\mathrm{MO}}$ speeds, flight spoilers deployed, and flight idling engines, an effective $E$ is in the range of 6 to 8. Vortex drag is reduced at high flight speeds with the parasitic drag and the wave drag being the chief contributors. For supersonic and hypersonic designs, the effective $E$ is lower and more in the 3-6 range. Such aircraft descend steeper and faster, but they also start at higher altitudes. An illustration of ED glide aerodynamics is shown in Figure 3. While having spoilers and landing gear $\left(\mathrm{V}_{\mathrm{LO}} / \mathrm{V}_{\mathrm{LE}}\right.$ limit) deployed with possibly some leading- and trailing-edge flaps/slats ( $\mathrm{V}_{\mathrm{FE}}$ limits) will result in a steeper descent, it will generally not be faster than in the configuration. The instantaneous angle-of-descent $\gamma$ is expressed by the airplane's flight speed and vertical speed or rate-of-descent (ROD) as:

$$
\sin \gamma=\frac{d z / d t}{v_{T A S}}=\frac{R O D \cdot \sqrt{\sigma(\theta)}}{v_{E A S}} .
$$

The instantaneous ROD is:

$$
R O D=\frac{v_{E A S} \cdot E_{e f f}^{-1}}{\sqrt{\sigma} \cdot(1+A F)} \quad A F=\frac{v_{T A S}}{g} \frac{d v_{T A S}}{d h} .
$$

Table 1. Acceleration factors for ISA troposphere and stratosphere

\begin{tabular}{llll}
\hline $\mathrm{AF}[-]$ & Speed/Mach regime & Altitude range $[\mathrm{km}]$ & TLR $[\mathrm{K} / \mathrm{m}]$ \\
\hline$+0.057 \mathrm{M}^{2}$ & $\mathrm{M}=$ const. & $32<\mathrm{H} \leq 47$ & +0.0028 \\
\hline$+0.020 \mathrm{M}^{2}$ & $\mathrm{M}=$ const. & $20<\mathrm{H} \leq 32$ & +0.001 \\
\hline 0 & $\mathrm{M}=$ const. & $11<\mathrm{H} \leq 20$ & 0 \\
\hline$-0.133 M^{2}$ & $\mathrm{M}=$ const. & $\mathrm{H} \leq 11$ & -0.0065 \\
\hline$+0.567 \mathrm{M}^{2}$ & EAS const. & $\mathrm{H} \leq 11$ & -0.0065 \\
\hline
\end{tabular}


The values of acceleration factors (AF) are summarized in Table 1 for various ISA layers with discrete TLRs (Daidzic 2015a). The instantaneous ROD, expressed through a constant Mach number and the SL speed of sound in air $a_{S L}$, is:

$$
R O D=\frac{d H}{d t}=\sin \gamma \cdot v_{T A S}=\frac{M \cdot a_{S L} \cdot \sqrt{\theta(H)}}{E_{e f f} \cdot(1+A F)} .
$$

Maximum airspeeds in an ED are limited by the $\mathrm{M}_{\mathrm{MO}} / \mathrm{V}_{\mathrm{MO}}$. Lower airspeeds can be used when necessary. A higher $\mathrm{V}_{\mathrm{MO}} / \mathrm{M}_{\mathrm{MO}}$, lower $E_{\text {eff; }}$, negative $\mathrm{AF}$, and warmer atmosphere all contribute to higher RODs. An airplane's $\mathrm{M}_{\mathrm{MO}} / \mathrm{V}_{\mathrm{MO}}$ ISA troposphere and stratosphere (up to $47 \mathrm{~km}$ ) ED speed schedule is illustrated in Figure 4. The ROD decreases during descent through the upper layers of the ISA stratosphere. Such a scenario is only appropriate for HST. The ROD (and TAS) will not change during the $\mathrm{M}_{\mathrm{MO}}$ descent in the ISA tropopause, but will increase for the $\mathrm{M}_{\mathrm{MO}}$ descent in the ISA troposphere reaching the maximum at $\mathrm{M}_{\mathrm{MO}} / \mathrm{V}_{\mathrm{MO}}$ transition after which the ROD decreases during a constant $\mathrm{V}_{\mathrm{MO}}$ (EAS) descent. A constant CAS-descent is not shown. Transients during descent entry are neglected. During the ED, the outside atmospheric pressure and density will be increasing. SST and HST will have a more complex descent profile, as they will have to slow down before entering a denser atmosphere. The ROD at $\mathrm{M}_{\mathrm{MO}}$ is directly obtained from Eq. (16). The ED speed schedule for a constant EAS $\mathrm{V}_{\mathrm{MO}}$ airspeed is given in Eq. (15). The change of atmospheric pressure due to airplane descent is: $d p_{a} / d t=\left(d p_{a} / d H\right) \cdot R O D$.

The crossover or changeover altitude at which the $\mathrm{M}_{\mathrm{MO}}$ descent morphs into the $\mathrm{V}_{\mathrm{MO}}$ descent (in knots) results in the non-dimensional pressure-ratio:

$$
\delta\left(H_{C H}\right)=\left(\frac{v_{M O}}{M_{M O} \cdot a_{S L}}\right)^{2}
$$

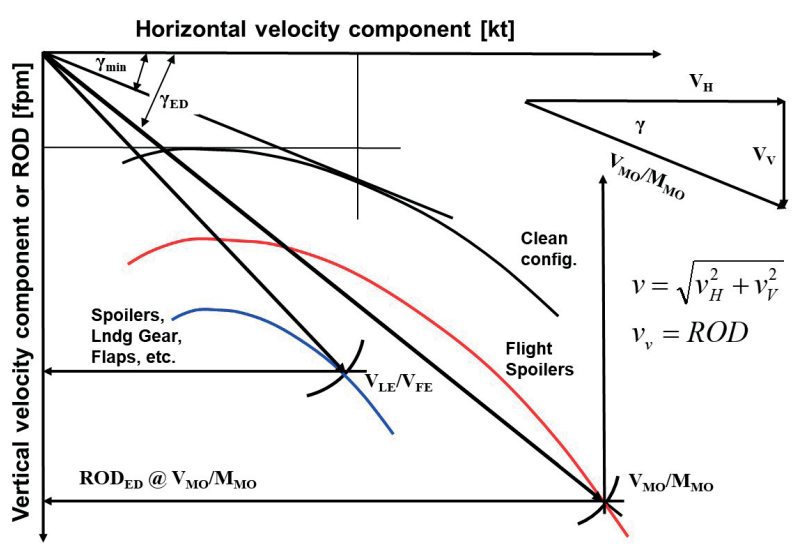

Fig. 3. Clean, high-speed ED, and slow-speed steep glide performance. Not to scale

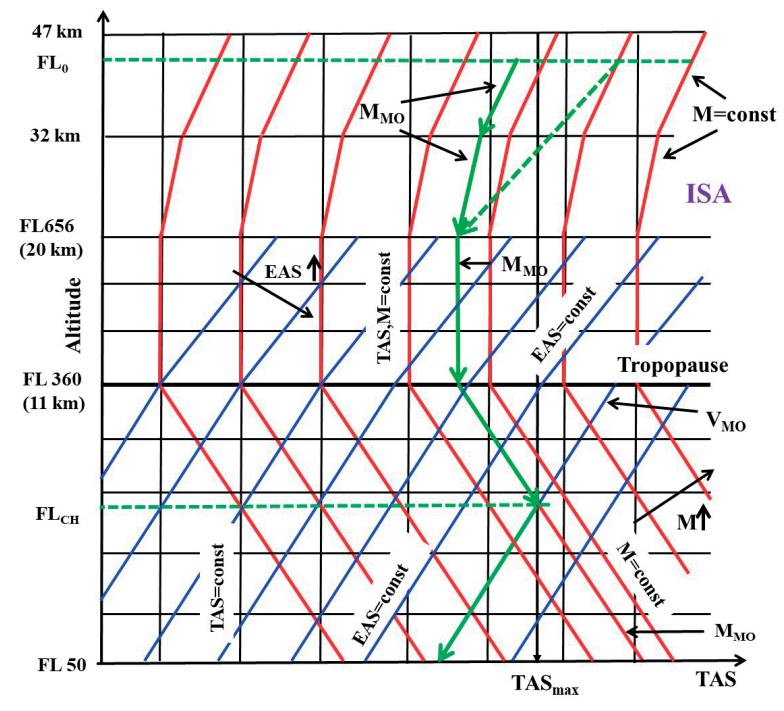

Fig. 4. $\mathrm{M}_{\mathrm{MO}} / \mathrm{V}_{\mathrm{MO}}$ ISA ED speed schedule. Not to scale

The changeover/crossover geopotential altitude is calculated from the NLPAM Eq. (6) by inverting it:

$H_{C H}=\frac{10^{5}}{2.30437}\left\{0.5789589-\tan \left[\frac{1}{6.86896} \cdot \ln \left(\frac{\delta_{C H} \cdot 10^{2}}{2.7191}\right)\right]\right\}[\mathrm{m}]$

For a $0.85 / 340$ descent, the changeover pressure is $\delta_{C H}=0.366$ and the changeover altitude is $7,864 \mathrm{~m}$ or $25,800 \mathrm{ft}$. The change of atmospheric pressure with height is obtained from the NLPAM or the ISOAM computations. For example, cabin versus flight altitude for a given constant cabin pressure differentials (PD) is calculated using the ISOAM for the cabin and the environmental atmosphere and is shown in Figure 5. The decompression event starts at point $A$ at the airplane's FL430 and a CA of 6,000 $\mathrm{ft}$ with the corresponding 9.0 psid $(62.05 \mathrm{kPa})$. While the flight crew is responding and preparing for an ED, the airplane's FL remains constant, while the CA increases until point $B$ where the ED actually starts. During the ED to FL100, the airplane's altitude decreases while the CA continues to increase until the $\mathrm{PD}$ is almost zero at point $C$. Point $C$ also designates the maximum $\mathrm{CA}$ reached. A negative pressure differential ( 0.5 psi or $3.45 \mathrm{kPa}$ ) develops and the cabin pressure is actually lower than the environmental one ("submarine" mode). The airflow reverses and is now inflow into the cabin (through NPRVs). In this case, the CA is actually somewhat "higher" than the airplane's altitude as the airplane and cabin descend from point $C$ to the level-off point $D$. The cabin air remains at a higher temperature than the atmospheric air due to ECS.

\section{Calculations and discussion of results}

Computations for subsonic, supersonic, and hypersonic aircraft cruising at various altitudes (about 12, 18, and 


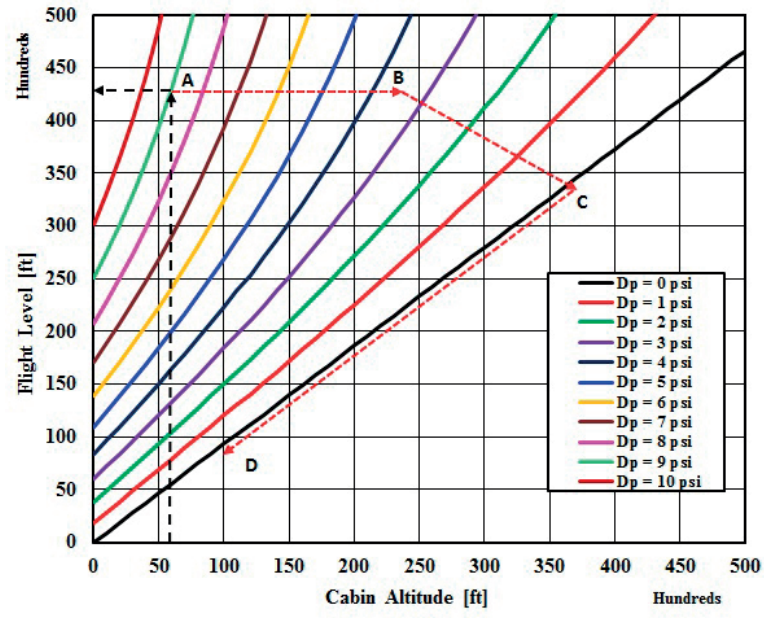

Fig. 5. ED dynamics with an ISOAM cabin and environmental atmospheres. Not to scale

$40 \mathrm{~km}$ ) having differing ED effective glide ratios and speed schedules were performed. Average ROCs were used to simulate the breach size, initial pressure differential, etc. The instantaneous RODs were calculated based on the airplane type and altitudes by using Eqs (15) and (16). The average AODs and RODs were calculated, when possible, analytically and numerically otherwise. The results of computations involving three different cruising altitudes with an equal initial CA of $6,000 \mathrm{ft}$ and a cabin ROC (25,000 fpm) are summarized in Table 2. The flight characteristics for subsonic transport are similar to a B767-300ER, while the the SST is similar to Concorde. No HST exists, so these computations are the best estimates for future hypersonic transport. The crew reaction time and the onset of the ED was equal in all three cases, i.e., 15 seconds. Clearly differing maximum CAs and times to reaching were obtained. Only the subsonic flight could meet the current regulatory limits. It took the SST only slightly longer to reach a breathable atmosphere, although it started at a 50\% higher altitude. The main culprit is a rather higher $\mathrm{M}_{\mathrm{MO}}$ for the SST. That is even more evident in the case of the HST descending at high Mach numbers. The effect of flight crew reaction and ED onset time just linearly shifts all times. As expected, higher maximum CAs are obtained.

The effect of decompression severity expressed through varying ROCs for subsonic aircraft flying at FL430 is summarized in Table 3. In all three cases, the NLPAM environmental pressure is about $2.56 \mathrm{psi}$, while the ISOAM cabin pressure for a $8,000 \mathrm{ft}$ is about 11.08 psi, resulting in a pressure differential of $8.525 \mathrm{psi}$. The average descent TAS is $482 \mathrm{kt}$. While the RODs, speeds, and AODs are identical in all three cases, differing maximum CAs were reached at different times. Only the first scenario fell within the regulatory limits, while both the $2^{\text {nd }}$ and the $3^{\text {rd }}$ case exceeded 2 minutes above FL250 and topped FL400 as well. The $3^{\text {rd }}$ case describes fast (almost rapid) decompression and the airplane is practically depressurized by the time the flight crew starts the ED. In reality, the AOD, TAS, ROD, and other parameters will be changing constantly due to the actual ambient atmosphere being dynamic with constantly varying TLRs. Nevertheless, the average effects and overall results are captured reasonably well with this model. The algebraic model was successfully tested against the known and recorded ED ROD profiles.

In Figure 6, a large number of ED calculations is summarized for a fictitious high-subsonic transport cruising at FL430, with the CA of 8,000 ft, and experiencing decompressions of varying magnitudes expressed by the average cabin ROCs. Curves do not represent time histories. The time to initiate a stabilized ED is fixed at 20 seconds. The design $\mathrm{V}_{\mathrm{MO}} / \mathrm{M}_{\mathrm{MO}}$ is $340 / 0.85$. The duration that the CA spends above FL250 is shown, and, for the average cabin ROCs above $15,000 \mathrm{fpm}$, it exceeds

Table 2. Decompression of subsonic, supersonic and hypersonic aircraft flying at respective operating altitudes with identical average cabin climbs and crew reaction times

\begin{tabular}{llll}
\hline & Subsonic & Supersonic & Hypersonic \\
\hline $\mathrm{FL}_{0}[\mathrm{~m} / \mathrm{ft}]$ & $12,192 / 40,000$ & $18,288 / 60,000$ & $39,929 / 131,000$ \\
\hline $\mathrm{CA}_{0}[\mathrm{~m} / \mathrm{ft}]$ & $1,829 / 6,000$ & $1,829 / 6,000$ & $1,829 / 6,000$ \\
\hline $\mathrm{T}_{\mathrm{ED}}[\mathrm{s}]$ & 15 & 15 & 15 \\
\hline $\mathrm{E}_{\mathrm{ED}}[-]$ & 7.5 & 6.0 & 4.0 \\
\hline $\mathrm{ROD}_{\mathrm{acft}}[\mathrm{fpm}]$ & 6,454 & 9,235 & 16,257 \\
\hline $\mathrm{AOD}_{\mathrm{acft}}[\mathrm{deg}]$ & 7.595 & 9.462 & 14.036 \\
\hline $\mathrm{ROC}_{\mathrm{CB}}[\mathrm{fpm}]$ & 25,000 & 25,000 & 25,000 \\
\hline $\mathrm{CA}_{\mathrm{max}}[\mathrm{ft}]$ & $34,305.9$ & $47,119.0$ & $84,207.8$ \\
\hline $\mathrm{T}_{\mathrm{PK}}[\mathrm{s}]$ & 67.93 & 98.69 & 187.70 \\
\hline$\Delta \mathrm{T}_{250}[\mathrm{~s}]$ & 108.84 & 196.79 & 360.62 \\
\hline$\Delta \mathrm{T}_{400}[\mathrm{~s}]$ & 0.00 & 63.34 & 269.26 \\
\hline $\mathrm{T}_{50}[\mathrm{~min}]$ & 5.67 & 6.21 & 8.00 \\
\hline
\end{tabular}


Table 3. Decompression of a particular subsonic aircraft experiencing different decompression magnitudes

\begin{tabular}{llll}
\hline & Subsonic & Subsonic & Subsonic \\
\hline $\mathrm{FL}_{0}[\mathrm{~m} / \mathrm{ft}]$ & $13,107 / 43,000$ & $13,107 / 43,000$ & $13,107 / 43,000$ \\
\hline $\mathrm{CA}_{0}[\mathrm{~m} / \mathrm{ft}]$ & $2,438 / 8,000$ & $2,438 / 8,000$ & $2,438 / 8,000$ \\
\hline $\mathrm{T}_{\mathrm{ED}}[\mathrm{s}]$ & 20 & 20 & 20 \\
\hline $\mathrm{E}_{\mathrm{ED}}[-]$ & 7.5 & 7.5 & 7.5 \\
\hline $\mathrm{ROD}_{\mathrm{acft}}[\mathrm{fpm}]$ & 6,454 & 6,454 & 6,454 \\
\hline $\mathrm{AOD}_{\mathrm{acft}}[\mathrm{deg}]$ & 7.595 & 7.595 & 7.595 \\
\hline $\mathrm{ROC}_{\mathrm{CB}}[\mathrm{fpm}]$ & 10,000 & 50,000 & 100,000 \\
\hline $\mathrm{CA}_{\mathrm{max}}[\mathrm{ft}]$ & $30,578.7$ & $40,904.0$ & $42,899.0$ \\
\hline $\mathrm{T}_{\mathrm{PK}}[\mathrm{s}]$ & 135.47 & 39.48 & 20.94 \\
\hline$\Delta \mathrm{T}_{250}[\mathrm{~s}]$ & 85.33 & 166.93 & 177.13 \\
\hline$\Delta \mathrm{T}_{400}[\mathrm{~s}]$ & 0.00 & 9.49 & 28.69 \\
\hline $\mathrm{T}_{50}[\mathrm{~min}]$ & 6.22 & 6.22 & 6.22 \\
\hline
\end{tabular}

the regulatory 2 minutes. For average ROCs above 6,000 fpm, the cabin FL250 is surpassed. The limiting FL400 is exceeded with the average cabin ROC of 40,000 fpm and higher. In the case of the most severe decompression, with an average 100,000 fpm cabin climb, it took just slightly over 20 seconds to entirely depressurize the aircraft. The algebraic model is not very accurate or realistic in the neighborhood of the peak time when reaching $\mathrm{CA}_{\max }$. In fact, the cabin air outflow will start decreasing and will be practically zero at $\mathrm{CA}_{\max }$. If the average cabin-climb rates are estimated accurately, the algebraic model is quite reasonable in its estimates.

The primary purpose of this article is to provide a methodology and a computational tool rather than conduct tedious parametric studies of infinite variations of depressurization events and ED dynamics. The algebraic model cannot give accurate pressure histories, but often that is not necessary. For better estimation of pressure histories, a differential model is required.

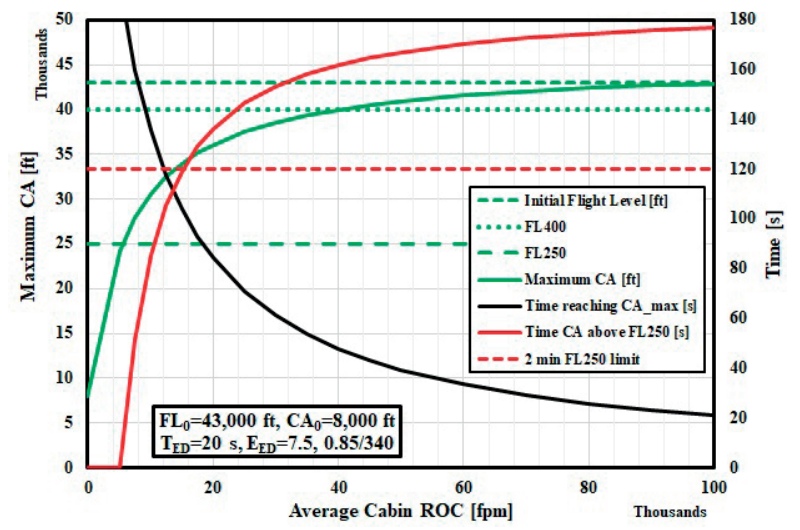

Fig. 6. ED computations for a subsonic airplane flying initially at FL430 with the CA of $8,000 \mathrm{ft}$
Hence, future model improvements will include 1D spatial modeling of the cockpit, cabin, cargo compartments and other pressurized compartments. The energy conservation differential equation will account for an arbitrary polytropic cabin air change accounting for diabatic flows with friction. The phase-change of the water-vapor in the cabin air will also be included. To account for the internal decompression dynamics, both passive and active valve dynamics must be modeled, as was done in Daidzic and Simones (2010), and in Pagani and Carrera (2016). The problem will be solved by numerically integrating a system of coupled nonlinear differential equations describing decompression dynamics and descent flight mechanics. The estimation of AFs for the ISOAM and NLPAM will be presented in another article.

\section{Conclusions}

We developed an algebraic model of aircraft decompression. An aerodynamic model of the ED maneuver to simulate an aircraft descending to a naturally breathable atmosphere after experiencing decompressions at 12, 18 and $40 \mathrm{~km}$, respectively, was incorporated. Only average RODs and AODs are used. The NLPAM model of the ambient atmosphere is implemented. The ISOAM model is used to simulate the cabin atmosphere during the EDs. The effect of the initial cabin altitude, flight level, breach size, and aircraft free air volumes were studied by using the average rates of cabin-altitude climbs. The flight crew reaction and ED onset times were also investigated. One of the stated goals was to explore the conditions under which the regulatory cabin altitude limits of FL250 and FL400 are exceeded. In general, future high-altitude supersonic and hypersonic cruisers cannot meet the existing aviation regulations on depressurization. Even contemporary subsonic jetliners cannot meet 
such regulations at higher flight levels at all times, and that was most likely the reason why the A380 received an exemption. The algebraic model cannot predict the temporal evolution of depressurization and descent histories accurately, but it does show the average effects reasonably well.

\section{References}

Bibel, G. 2008. Beyond the black box: the forensics of airplane crashes. Baltimore, MD: The Johns Hopkins University Press.

Daidzic, N. E.; Simones, M. 2010. Aircraft decompression with installed cockpit security door, Journal of Aircraft 47(2): 490-504. https://doi.org/10.2514/1.41953

Daidzic, N. E. 2010. Future hypersonic, suborbital, and orbital travel in business aviation, in Education Session II of the UAA Conference, 5-7 October 2010, Crowne Plaza, St. Paul, MN, USA.

Daidzic, N. E. 2011. Designing propulsion systems for future Air/Space transportation, Professional Pilot 45(9): 82-86.

Daidzic, N. E. 2015a. Efficient general computational method for estimation of standard atmosphere parameters, International Journal of Aviation Aeronautics and Aerospace 2(1): $1-37$.

Daidzic, N. E. 2015b. Global optimized isothermal and nonlinear models of Earth's standard atmosphere, International Journal of Aviation Aeronautics and Aerospace 2(3): 1-43.

Daidzic, N. E. 2016. Estimation of performance airspeeds for high-bypass turbofans equipped transport-category airplanes, Journal of Aviation Technology and Engineering 5(2): 27-50. https://doi.org/10.7771/2159-6670.1122

Davies, D. P. 1971. Handling the big jets. Civil Aviation Authority (UK), London, United Kingdom.

Filippone, A. 2007. Steep-descent maneuver of transport aircraft, Journal of Aircraft 44(5): 1727-1739.

https://doi.org/10.2514/1.28980

Gooch, T. R. 1993. 757/767: The mysteries revealed. Aurora, CO: Author.

Hunt, E. H.; Space, D. R. 1994. The airplane cabin environment: issues pertaining to flight attendant comfort, International In-flight Service Management Organization Conference, November 1994, Montreal, Canada.

Hunt, E. H.; Reid, D. H.; Space, D. R.; Tilton, F. E. 1995. Commercial airliner environmental control system: engineering aspects of cabin air quality, in Aerospace Medical Association Annual Meeting, May 1995, Anaheim, California.

Jeppesen. 2007. Airframes and systems. JAA ATPL JAR Ref. 021 01. 2nd ed. Jeppesen Sanderson Inc., Neu-Isenburg, Germany.

Lowry, J. T. 2002. Calculating flight paths of not necessarily small inclination, Journal of Aircraft 40(2): 410-412. https://doi.org/10.2514/2.3114

Macarthur, J. 1994. Air disaster: the cost of solving the Comet mystery must be reckoned neither in money nor in manpower. BOAC DH-106 Comet 1 G-ALYP on January 10, 1954 and BOAC DH-106 Comet 1 G-ALYY on April 8, 1954, Chapter 1, Volume 1. Weston Creek, Australia: Aerospace Publications Pty Ltd.
Moir, I.; Seabridge, A. 2008. Aircraft systems: mechanical, electrical, and avionics subsystems integration. 3rd ed. Chichester, UK: John Wiley \& Sons. https://doi.org/10.1002/9780470770931

Moir, I.; Seabridge, A. 2013. Design and development of Aircraft systems. 2nd ed. Chichester, UK: John Wiley \& Sons.

Moir, I.; Seabridge, A.; Jukes, M. 2013. Civil avionics systems. 2nd ed. Chichester, UK: John Wiley \& Sons. https://doi.org/10.1002/9781118536704

Pagani, A.; Carrera, E. 2016. Gasdynamics of rapid and explosive decompressions of pressurized aircraft including active venting, Advances in Aircraft and Spacecraft Science 3(1): 77-93. https://doi.org/10.12989/aas.2016.3.1.077

Ray, M. 1999. The Boeing 737 simulator checkride survival manual. Temecula, CA: University of Temecula Press.

Ray, M. 2000. The Boeing 757-767 simulator checkride procedures manual. Temecula, CA: University of Temecula Press.

Trenberth, K. E.; Smith, L. 2005. The mass of the atmosphere: a constraint on global analysis, Journal of Climate 18: 864875. https://doi.org/10.1175/JCLI-3299.1

US Department of Transportation, Federal Aviation Administration (FAA). 1996. Pressurization, ventilation and oxygen systems assessment for subsonic flight including high altitude operation. Advisory Circular AC 25-20. US Department of Transportation, Federal Aviation Administration, Washington, DC.

US Department of Transportation, Federal Aviation Administration (FAA). 2005. Fuselage doors and hatches. Advisory Circular AC 25.783-1A. US Department of Transportation, Federal Aviation Administration, Washington, DC.

US Department of Transportation, Federal Aviation Administration (FAA). 2012. Flight test guide for certification of transport category airplanes. Advisory Circular AC 25-7C, 10/16/2012. US Department of Transportation, Federal Aviation Administration, Washington, DC.

US Department of Transportation, Federal Aviation Administration (FAA). 2014. Part 121, Operating requirements: domestic, flag, and supplemental operations. US Department of Transportation, Federal Aviation Administration, Washington, DC.

US Department of Transportation, Federal Aviation Administration (FAA). 2015a. Part 25, Airworthiness Standards: Transport Category Airplanes. US Department of Transportation, Federal Aviation Administration, Washington, DC.

US Department of Transportation, Federal Aviation Administration (FAA). 2015b. Aircraft Operations at Altitudes Above 25,000 Feet Mean Sea Level or Mach Numbers Greater Than.75. Advisory Circular AC 61-107B with change 1, 9/9/15. US Department of Transportation, Federal Aviation Administration, Washington, DC.

Webb, J.; Walker, B. 2004. Fly the wing. 3rd ed. Oxford, United Kingdom: Blackwell.

Whipple, F. 1963. On meteoroids and penetration, Journal of Geophysical Research 68(17): 4929-4939.

https://doi.org/10.1029/JZ068i017p04929

Wild, T. W. 1996. Transport category aircraft systems. Englewood, CO: Jeppesen. 